\title{
INFLUÊNCIA DA ARQUITETURA NO AMBIENTE ESCOLAR: PROJETO DE UMA
}

\section{ESCOLA NO MUNICÍPIO DE CAÇADOR}

\author{
Pablo Santin ${ }^{1}$ \\ Cláudia Maté ${ }^{2}$ \\ Patrícia Costa Pellizzaro 3
}

\section{RESUMO}

O presente artigo analisa aspectos da arquitetura escolar, apontando pontos importantes na concepção de um ambiente adequado as atividades de ensino e aprendizado, aspectos que podem transforma-lo em um espaço mais acolhedor, dinâmico e interativo, fugindo dos padrões do ensino tradicional replicado na maioria das escolas públicas brasileiras. Na sequência é apresentado um breve estudo do projeto de implantação do ensino integral nas escolas públicas, que tem proporcionado aos estudantes o desenvolvimento de suas habilidades, oferecendo além das disciplinas obrigatórias, atividades culturais e de oficinas, diminuindo assim o índice de analfabetismo e jovens nas ruas. Para tanto é necessário entender o ambiente escolar e as novas demandas de espaço para relacionar a arquitetura com o ensino, promovendo assim que as áreas se integrem com o objetivo do programa do Governo Federal de oferecer um ensino de qualidade a todas as crianças e jovens. Visando verificar a influência da arquitetura no ambiente escolar foram analisadas duas escolas, sendo estas: Escola de Ensino Médio, Irmão Leo, em Caçador, e a escola Positivo internacional, em Curitiba, onde foram levantados os pontos positivos e negativos em relação a sua estrutura física e os seus ambientes. A diferença nas salas de aulas, como os mobiliários, áreas de convivência, sendo que uma possui e o outra não, todos os materiais utilizados com um melhor

\footnotetext{
${ }^{1}$ Acadêmico do Curso de Arquitetura e Urbanismo da Universidade Alto Vale do Rio do Peixe (UNIARP). E-mail: pablosantinm7@hotmail.com.

2 Professora orientadora. Doutoranda em Arquitetura e Urbanismo pela Universidade Federal de Santa Catarina (UFSC). e Graduação em Arquitetura de Urbanismo pela Universidade Federal de Santa Catarina (UFSC).claudiaamate@gmail.com

${ }^{3}$ Professora Orientadora. Doutora em Gestão Urbana pela Pontifícia Universidade Católica do Paraná (PUCPR). Graduação em Arquitetura e Urbanismo pela Pontifícia Universidade Católica do Paraná (PUCPR).patricia.pellizzaro@gmail.com
} 
aproveitamento e aplicação entre outros. Na sequência foi realizada a análise comparativa dos dois casos, de modo a obter subsídios para propor diretrizes inovadoras e espaços diversificados, proporcionando aos estudantes uma ambiência dinâmica para o desenvolvimento das suas capacidades, deixando para atrás o padrão de escolas fechadas e muradas.

Palavras-Chave: Arquitetura escolar. Ensino integral. Escolas planejadas.

\section{ABSTRACT}

This article analyzes aspects of school architecture, pointing out important points in the design of an adequate environment teaching and learning activities, aspects that can turn it into a more welcoming, dynamic and interactive space, avoiding the patterns of traditional teaching replicated in the majority of Brazilian public schools. The following is a brief study of the implementation of integral education in public schools, which has provided students with the development of their skills, offering compulsory courses, cultural activities and workshops, thus reducing the illiteracy rate and youth in the schools. streets. To do so, it is necessary to understand the school environment and the new demands of space to relate the architecture with the teaching, thus promoting that the areas integrate with the objective of the program of the Federal Government to offer a quality education to all the children and young people. Aiming to verify the influence of the architecture in the school environment, two schools were analyzed: High School, Brother Leo in Caçador, and the Positivo internacional school in Curitiba, where positive and negative points were raised regarding its structure physics and their environments. The difference in classrooms, such as furniture, living areas, one has and the other does not, all materials used with a better use and application among others. A comparative analysis of the two cases was carried out, in order to obtain subsidies to propose innovative guidelines and diverse spaces, giving the students a dynamic environment for the development of their capacities, leaving behind the pattern of closed and walled schools.

Keywords: School architecture. Integral education. Planned Schools.

\section{INTRODUÇÃO}

Este artigo aborda o tema das escolas atuais com o ensino integral, como a arquitetura pode transformar e influenciar no aprendizado dos estudantes, e de que forma o ambiente escolar afeta o ensino.

O ensino integral implantando pelo Governo Federal, nas escolas públicas 
brasileiras, fornece uma ampla área de conhecimentos, sendo desenvolvidos diversas atividades, disciplinas específicas, aulas culturais e oficinas, no entanto é necessário um ambiente adequado para essa troca e construção do conhecimento (LINS, 2017).

O espaço educativo tradicional, como a sala de aula, deixa de ser considerado como o único ambiente de aprendizagem, outros lugares são necessários para o estudo, onde não se limite apenas por paredes fechadas, e sim que os alunos possam explorar um espaço diversificado, dinâmico e atrativo.

Com atividades variadas, além das disciplinas obrigatórias, o desenvolvimento motor, físico e emocional de crianças e jovens é afetado diariamente, por isso, o espaço não deve ser cansativo e maçante, as sete horas por dia deve ser bem aproveitada, bem como os lugares onde essas atividades são executadas.

Segundo o relatório para UNESCO da Comissão Internacional sobra a Educação para o século XXI - Educação: um tesouro a descobrir (DELORS et al, 2010), a educação está fundamentada em quatro pilares: aprender a conhecer, aprender a fazer, aprender a viver junto, aprender a ser. Estes quatro pilares são fundamentais para a formação de um indivíduo socialmente competente, capaz de pensar, fazer, se comunicar e questionar. No entanto, a educação tradicional no Brasil se concentra no pilar aprender a conhecer, ou seja, no acumulo e memorização de informações. Grande parte das escolas brasileiras ainda são projetadas de acordo com o ensino tradicional, que prioriza ainda o conteúdo e a memorização

Com as novas diretrizes governamentais tem-se a necessidade, e oportunidade, de criação de novas escolas, buscando interação social, entre educadores, alunos e a comunidade.

É importante entender a relação existente entre o ensino e a arquitetura para o desenvolvimento de um ambiente escolar adequado, proporcionando aos estudantes uma ambiência dinâmica para o desenvolvimento das suas habilidades, deixando para atrás o padrão de escolas fechadas e muradas, dando mais liberdade para que alunos e docentes possam usufruir de um espaço mais confortável.

O objetivo geral deste artigo é estudar a relação da arquitetura e educação, relacionando o ensino e a arquitetura escolar, possibilitando um espaço adequado e integrado, fazendo com que os estudantes desenvolvam as suas habilidades, 
adquiram conhecimento, e um ambiente que favoreça tanto seu aprendizado quanto o desempenho dos seus professores, proporcionando uma experiência única e valiosa.

\section{REFERENCIAL TEÓRICO}

Neste capítulo são apresentados aspectos relacionados à educação pública brasileira, mais especificamente as escolas de ensino integral, e sua relação com o ambiente escolar e sua influência nos processos de ensino e aprendizagem.

\section{A ESCOLA EM TEMPO INTEGRAL}

O ambiente escolar é mais do que apenas salas de aulas e as matérias obrigatórias. Hoje as escolas possuem um corpo docente preparado com professores, diretores, psicólogos e demais funcionários que atuam e acrescentam muito na vida de cada aluno, o colégio é uma extensão dos seus lares onde se aprende também a viver em sociedade, aliando os conhecimentos para viver e trabalhar na mesma (TEIXEIRA, 1962, apud TENÓRIO,2011).

O ensino integral brasileiro é composto por três programas, são eles: Mais Educação que abrange as crianças do ensino fundamental, Ensino Médio Inovador que abrange os jovens e adolescentes e tem também o programa de educação infantil integral que abrange crianças de zero a cinco anos (MEC, 2018).

Ambos os projetos inserem atividades e conteúdos dinâmicos, possibilitando o desenvolvimento de diversas áreas do conhecimento, o ensino integral foi criado para diminuir o índice de crianças e jovens nas ruas, dando a elas a oportunidade de crescimento profissional e cultural (MEC, 2018).

As fases iniciais da vida do ser humano são passadas dentro de uma escola, portanto é de suma importância, pensar no espaço, pois, é nesse período que o indivíduo vai desenvolver suas principais habilidades intelectuais, motoras e até mesmo sentimentais, sendo a escola seu primeiro contato em sociedade (MEC, 2018). 
ENSINO INTEGRAL NO BRASIL

O ensino integral tem a necessidade de ampliar o período que as crianças, adolescentes e jovens passam nas escolas, com a oferta de atividades formativas e ambientes propícios ao seu desenvolvimento (MEC,2007).

Segundo MEC (2007) a diversificação das ações pedagógicas obtém um melhor rendimento escolar, automaticamente diminuindo a evasão e reprovação dos alunos, oferecendo atendimento exclusivo para as crianças, adolescentes e jovens com alguma necessidade especial, contribuindo assim para a integração dos alunos com os colegas e até mesmo com a própria sociedade, com essas práticas conseguem prevenir e combater o trabalho infantil. As aulas artísticas e a prática de esportes aproximam os alunos da adversidade cultural do Brasil e do mundo, trazendo novos conhecimentos das demais regiões através da arte e do esporte.

São previstas 572 unidades de ensino médio aprovadas em todos os estados, dentre as quais 30 em Santa Catarina, permitindo 257.400 novas matriculas. Estas unidades deverão ser implantadas entre os anos de 2017 até 2020 (MEC, 2017).

De acordo com o MEC (2017) o programa foi criado para aumentar o tempo de aula dos estudantes, demais objetivos já mencionados e diminuir os baixos índices na qualidade do ensino do Brasil.

ENSINO INTEGRAL EM SANTA CATARINA

O ensino constantemente evolui trazendo bons resultados, sendo percebidos não só pelos alunos e diretores, mas o governo também, mostrando que os investimentos estão sendo empregados da forma correta, e tornando viável a transição do ensino regular para o integral.

O número de estudantes do ensino médio chegou a 174 mil nas escolas estaduais em 2017. Os resultados positivos foram frutos dos inúmeros projetos que estão dentro das modalidades oferecidas em Santa Catarina, entre elas o Ensino Médio regular, Ensino Médio Profissionalizante (EMIEP), Ensino Médio Inovador (EMI) e Ensino Médio Integral em Tempo Integral (EMITI) ofertadas em cerca de 800 unidades da rede. Com a diretriz de oferecer oportunidades de construção conjunta de uma educação que valoriza o aprendizado de conteúdos tradicionais, 2017 ampliou a oferta com o Ensino Médio Integral em Tempo integral, finalizando o ano letivo com bons resultados. Ao todo 
foram atendidos 1.139 alunos em 15 escolas catarinenses. "Do ponto de vista pedagógico, tivemos um resultado fantástico, tendo como base a melhora da média dos alunos, nos projetos integradores que estão sendo feitos, inclusive mudando a realidade da escola. O que ajudou a dobrarmos o número de escolas em tempo integral em 2018, passando de 15 para 34", destaca o secretário de Estado da Educação, Eduardo Deschamps. (CANELLO,2017).

Segundo Lima (2018) a proposta de educação integral para ensino médio no estado iniciou no ano de 2017, tendo como base as diretrizes do ministério da educação. As escolas que atenderam os requisitos e foram escolhidas para participarem, possuem capacidade para atender aproximadamente 13.500 alunos em 30 instituições espalhadas nas 25 cidades sedes.

A partir da análise da Figura 1 verifica-se que poucas cidades que conseguiram aprovação para dar início com o programa de ensino integral nas escolas de ensino médio, em um total de 295 municípios apenas 25 estão sendo contempladas.

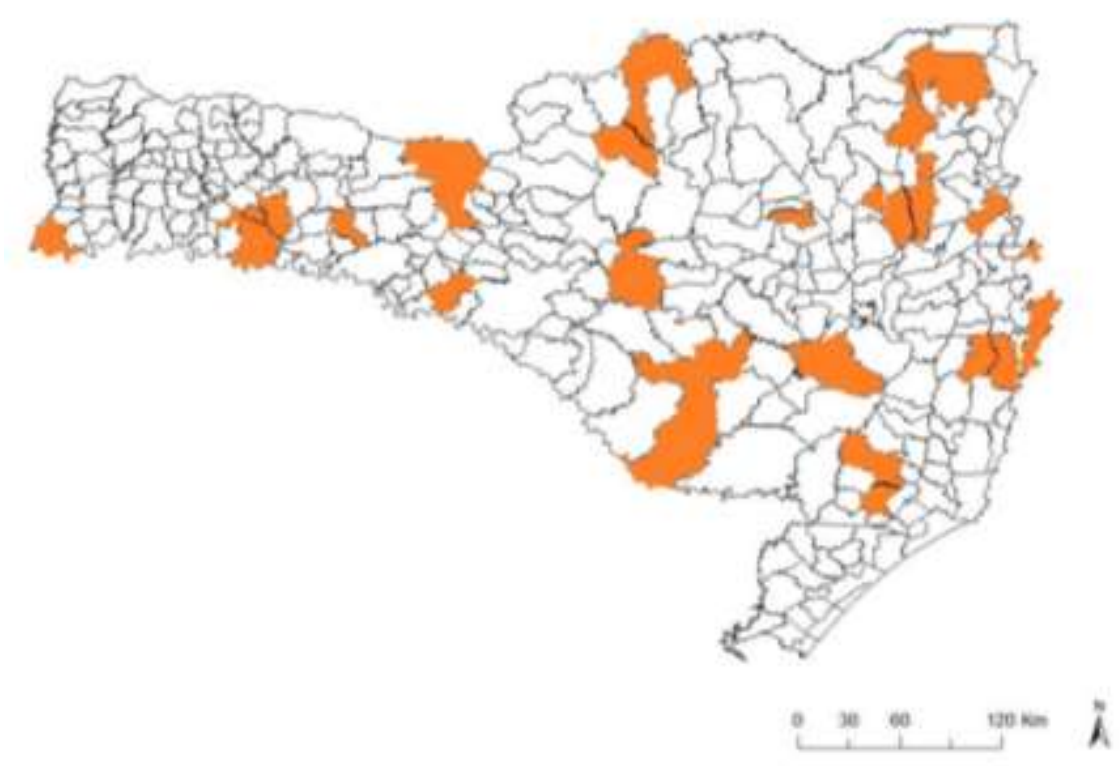

Figura 1 - Distribuição das escolas de ensino médio integram em Santa Catarina Fonte: Elaborado com base em MEC (2018)

É possível verificar que estes estão distribuídos por todo território estadual, compreendendo municípios de pequeno e grande porte. 
ENSINO INTEGRAL EM CAÇADOR

No município de Caçador, o ensino integral foi implantado na primeira etapa do programa ensino médio em tempo integral no ano de 2012, os dois colégios escolhidos foram Irmão Léo e Wanda Krieger Gomes.

A escola jovem de ensino médio Irmão Leo está situada no centro da cidade de caçador, uma excelente localização, possui ponto de ônibus próximo, uma região com maior infraestrutura, movimento, segurança e de fácil acesso. Iniciou o programa com cinco turmas, contendo 30 alunos cada sala de aula, totalizando uma capacidade máxima de 150 alunos do ensino médio.

A escola estadual de educação básica Wanda Krieger Gomes tem suas instalações no bairro Martello, loteamento Recanto da Alvorada, uma localização com pouca infraestrutura no seu entorno e distante do centro da cidade.

Durante o período que o programa funcionou os alunos tinham diariamente nove aulas por dia, somando 45 aulas semanais, com disciplinas da base curricular nacional comum, língua estrangeira moderna, língua estrangeira optativa, projetos de vida, projetos de intervenção, pesquisas e estudos orientados. Fazendo três refeições diária, café da manhã, almoço e café da tarde (PORTAL CDR, 2012).

Ambas as escolas, em 2015, encerraram o programa de ensino médio em tempo integral, devido à falta de alunos com interesse no programa. Um dos maiores motivos é a pressão econômica exercida nas famílias dos estudantes, fazendo com que eles tenham que abandonar o estudo integral e ter que ir em busca de emprego para complementar a renda das suas famílias, o programa na cidade de caçador acabou perdendo espaço para a o trabalho infantil.

\section{EDUCAÇÃO E ARQUITETURA}

No início a educação pública no Brasil era para ser igualitária entre todas as pessoas, porém, na primeira república funcionou de maneira diferente, o programa educacional público foi direcionado apenas para ensino elementar, que nos dias atuais seria o ensino fundamental, enquanto o secundário ficava apenas disponível para uma pequena parte da população, as elites, ministradas por instituições privadas (BASTOS, 2009).

A educação vem sofrendo algumas transformações importantes, 
principalmente nos últimos 50 anos, onde o modelo tradicional, hierárquico e rígido vem dando espaço para um sistema mais flexível, onde tanto o professor quanto os alunos possuem mais liberdade (KOWALTOWSKI, 2010). No entanto, conforme a autora, o modelo predominante no Brasil, principalmente no ensino público, ainda é o tradicional, com carteiras enfileiradas para manter a ordem e o silencio. A autora explica que a adequação dos espaços escolares aos novos pensamentos pedagógicos é fundamental e esta tarefa cabe aos arquitetos.

A escola deve ser um lugar prazeroso de frequentar, mas se elas não são bem conservadas e fechadas, acabam causando insegurança nos estudantes. Outro fator que impede o aluno de se concentrar nas disciplinas são as intempéries climáticas, fazendo com que se distraiam com facilidade, perdendo a concentração, além de causar desconforto (KOWALTOWSKI, 2018).

Pesquisas feitas na Inglaterra no ano de 2015, apontam que os estudantes que tiveram resultados positivos nas provas possuem uma infraestrutura de qualidade, enquanto os estudantes que obtiveram notas inferiores, tem escolas pouco cuidadas. Diante disso pode-se dizer que o ambiente escolar tem sua importância na vida dos jovens, não apenas para melhorar seu desempenho, mas, incentivar os alunos ao estudo e a prática de atividades diversificadas (KOWALTOWSKI, 2018).

A edificação escolar, por sua importância pedagógica, é vista por muitos educadores como um terceiro professor, sendo o professor o primeiro e o segundo o material didático (KOWALTOWSKI, 2011). A autora defende que a escola atual deve se adequar aos novos métodos de ensino, em que o foco está no estudante e sua relação com o meio. Assim, deve estimular a interação e socialização e oferecer espaços flexíveis que possam ser modificados de acordo com as atividades realizadas (KOWALTOWSKI, 2011).

De acordo com Duarte (2009) apud Bastos (2009) seria de suma importância as escolas não se limitarem apenas no seu uso convencional durante a semana, e sim suas portas serem abertas para a sociedade fazer uso nos finais de semana como um centro social do bairro, assim multiplicando o seu uso e automaticamente enriquecendo o ambiente.

As escolas tradicionais foram construídas, por muito tempo, seguindo o mesmo projeto padrão, utilizando dos mesmos materiais e formas, para se 
adequarem aos valores das licitações proposta pelo governo. O papel do arquiteto no processo de projeto de escolas envolve não só o conhecimento e aplicação da estratégia pedagógica escolar, mas também os aspectos físicos e sociais da comunidade alvo, tais elementos são essenciais para a definição do programa de necessidades de uma edificação escolar (KOWALTOWSKI, 2011).

Os projetos arquitetônicos escolares devem ser estudados e pensados com um único propósito, o aluno, (criança e jovem), o motivo maior para existir toda essa grande máquina da educação. Um projeto escolar deve buscar o equilíbrio entre os aspectos pedagógicos e arquitetônicos.

Para que a arquitetura auxilie na aprendizagem, é importante considerar diversos aspectos na etapa de desenvolvimento do projeto. O conforto ambiental que envolve aspectos como qualidade do ar, temperatura, ventilação, iluminação e acústica, possui forte relação com a produtividade e aprendizagem (BASTOS, 2009). O autor ainda defende que, sempre que for possível, é fundamental trazer a natureza junto as salas e demais instalações escolares, e torná-lo mais agradável (BASTOS, 2009).

A prática esportiva é um aspecto positivo no ensino, além do aprendizado teórico, desenvolve suas habilidades motoras. A quadra de esportes, no entanto influência nas dimensões da edificação, se não for executado da forma correta pode trazer consequências como o mal desempenho da acústica na estrutura, pois, o isolamento das vibrações sonoras demanda de uma alta qualidade construtiva. Com a modalidade de licitação e baixos custos, acaba por não ser executado da maneira desejada (KOWALTOWSKI, 2011).

A nova arquitetura escolar só vai se tornar realidade se todos fazerem sua parte, espírito de coletividade entre alunos, professores, funcionários e demais colaboradores. Tudo deve ser consultado antes de executar, pois, a opinião de todos vai sempre colaborar para que o projeto escolar seja uma constante evolução. (GOULART, 2016). 


\section{ESTUDO DE CAMPO}

\section{ANÁLISE DA INFLUÊNCIA DA ARQUITETURA NO AMBIENTE ESCOLAR}

As influências da arquitetura no ambiente escolar foram identificadas a partir da análise de dois estudos de caso:

a) Escola Jovem de Ensino Médio Irmão Leo - visando verificar a realidade do município de Caçador, selecionada por ter integrado o programa de ensino médio integral entre os anos de 2013 e 2015;

b) Escola Positivo Internacional - observando a estrutura de qualidade de uma escola particular que atende estudantes do Brasil e de outros países, mostrando que é possível projetar e executar da melhor forma, ambientes pensados nos estudantes não só de escolas particulares, mas públicas também.

\section{ESCOLA JOVEM DE ENSINO MÉDIO IRMÃO LÉO}

A análise desta escola foi realizada por meio de levantamento de campo, a visita ocorreu no dia 04 de junho de 2018. Foram verificados os aspectos que necessitam ser adequados ou melhorados e os pontos que estão de acordo com as diretrizes estabelecidas pelo MEC para o ensino médio integral. Os principais pontos levantados são apresentados no Quadro 1. 
Quadro 1 - Síntese analítica da Escola Jovem de Ensino Médio Irmão Leo

(Continuação para as próximas páginas)

\begin{tabular}{|c|c|c|}
\hline Setores & Pontos positivos ou negativos & Registro fotográfico \\
\hline $\begin{array}{l}\text { Área } \\
\text { externa }\end{array}$ & $\begin{array}{l}\text { Ponto positivo: Possui uma grande área para } \\
\text { estacionamento, deixando os veículos dos } \\
\text { professores e colaboradores seguros. } \\
\text { Ponto negativo: O estacionamento não tem } \\
\text { cobertura ligando a entrada da do colégio, } \\
\text { deixando os usuários nos dias de chuva e frio } \\
\text { totalmente desprotegidos. }\end{array}$ & $\rightarrow 0$ \\
\hline $\begin{array}{l}\text { Área } \\
\text { externa }\end{array}$ & $\begin{array}{l}\text { Ponto positivo: Existe uma guarita para } \\
\text { recepcionar e proteger os estudantes de uma } \\
\text { eventual invasão indesejada. } \\
\text { Ponto negativo: Devido a falta de manutenção } \\
\text { está inativa, com problemas estruturais de } \\
\text { infiltração na laje. Impossibilitando a utilização } \\
\text { do ambiente. }\end{array}$ & \\
\hline $\begin{array}{l}\text { Área } \\
\text { externa }\end{array}$ & $\begin{array}{l}\text { Ponto positivo: Existe uma rampa de acesso } \\
\text { para os cadeirantes } \\
\text { Ponto negativo: Não existe sinalização para } \\
\text { novos estudantes e as adequações para os } \\
\text { deficientes visuais. }\end{array}$ & \\
\hline $\begin{array}{l}\text { Área } \\
\text { externa }\end{array}$ & $\begin{array}{l}\text { Ponto negativo: Falta de um mobiliário } \\
\text { adequado para permanecer na área externa } \\
\text { sem sofrer com ação do tempo e um grande } \\
\text { espaço sem utilização que poderia ser } \\
\text { desenvolvido diversas atividades. }\end{array}$ & $\vec{i}$ \\
\hline
\end{tabular}


(Continuação para as próximas páginas)

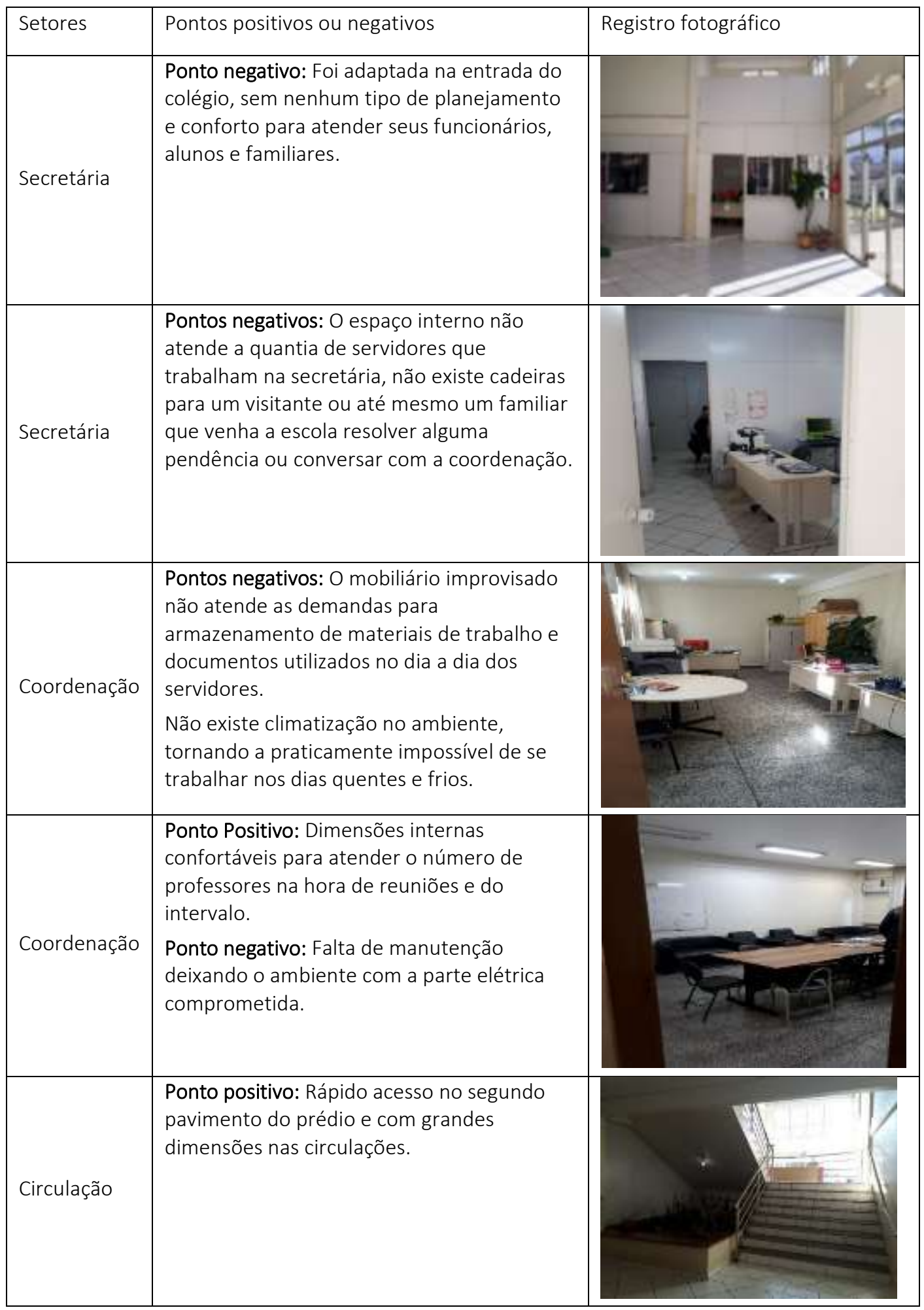




\begin{tabular}{|c|c|c|}
\hline Setores & Pontos positivos ou negativos & Registros fotográficos \\
\hline & $\begin{array}{l}\text { Ponto positivo: Existe uma preocupação com } \\
\text { os usuários que utilizam cadeiras de roda ou } \\
\text { com algum tipo de mobilidade reduzida. }\end{array}$ & \\
\hline Circulação & $\begin{array}{l}\text { Pontos negativos: Os corredores não } \\
\text { possuem ventilação cruzada e as aberturas } \\
\text { para iluminação natural são pequenas, } \\
\text { impactando diretamente no conforto } \\
\text { térmico do prédio. }\end{array}$ & \\
\hline Circulação & $\begin{array}{l}\text { Ponto negativo: Os alunos quando precisam } \\
\text { desenvolver algum tipo de atividade feita } \\
\text { fora da sala de aula, não tem um espaço } \\
\text { específico para exposição de trabalhos, } \\
\text { restando apenas os corredores para utilizar. }\end{array}$ & \\
\hline Sala de aula & $\begin{array}{l}\text { Pontos positivos: Possuem grandes janelas, } \\
\text { ventilando bem o ambiente e tem uma } \\
\text { dimensão confortável para abrigar até } 30 \\
\text { alunos. } \\
\text { Ponto negativo: O mobiliário é antigo e não } \\
\text { atende as normas para ergonomia dos } \\
\text { alunos e professores, impactando } \\
\text { diretamente na saúde deles. }\end{array}$ & \\
\hline Laboratório & $\begin{array}{l}\text { Pontos negativos: Mobiliário não é } \\
\text { confortável e não é o correto para } \\
\text { laboratórios de química e biologia. Não } \\
\text { existe os equipamentos para desenvolver as } \\
\text { aulas práticas além das teóricas. }\end{array}$ & 10 \\
\hline
\end{tabular}


(Continuação para as próximas páginas)

\begin{tabular}{|c|c|c|}
\hline Setores & Pontos positivos ou negativos & Registros fotográficos \\
\hline Laboratório & $\begin{array}{l}\text { Ponto negativo: Problemas na rede elétrica do } \\
\text { prédio impossibilitam a utilização correta do } \\
\text { laboratório de informática com todos os } \\
\text { equipamentos necessários. }\end{array}$ & \\
\hline Leitura & $\begin{array}{l}\text { Pontos negativos: Sala tem dimensões pequenas } \\
\text { para a prática de leitura, fica localizada no } \\
\text { segundo pavimento, distante da biblioteca e com } \\
\text { mobiliário impróprio. }\end{array}$ & \\
\hline Biblioteca & $\begin{array}{l}\text { Pontos negativos: Existe pouco espaço para } \\
\text { guardar os livros e circular ao redor das } \\
\text { prateleiras, a proteção contra a insolação é feita } \\
\text { com cortinas inapropriadas e adaptadas. }\end{array}$ & \\
\hline Refeitório & $\begin{array}{l}\text { Ponto positivo: Tem bastante ventilação e } \\
\text { iluminação entrando no ambiente. } \\
\text { Pontos negativos: Não atende o número de } 150 \\
\text { alunos fazendo uma refeição. O desconforto de } \\
\text { ficar mesas amontoadas é muito grande e } \\
\text { perigoso quando se tem um alimento quente. }\end{array}$ & \\
\hline Cozinha & $\begin{array}{l}\text { Ponto negativo: Não existe o lugar adequado } \\
\text { para o preparo dos alimentos, sendo usado uma } \\
\text { mesa móvel para atender as necessidades }\end{array}$ & \\
\hline Banheiro & $\begin{array}{l}\text { Ponto negativo: Todos os banheiros não foram } \\
\text { feitos e adaptados para os portadores de } \\
\text { deficiência física e visual. }\end{array}$ & \\
\hline
\end{tabular}




\begin{tabular}{|l|l|l|}
\hline \multicolumn{3}{|c|}{ (Conclusão) } \\
\hline Setores & Pontos positivos ou negativos & $\begin{array}{l}\text { Pontos positivos: Existe uma quadra de } \\
\text { esporte coberta onde são desenvolvidas } \\
\text { todas as atividades de esportes e lazer. } \\
\text { Pontos negativos: Não está de acordo com } \\
\text { as normas de segurança exigidas pelos } \\
\text { bombeiros e o sistema elétrico está } \\
\text { comprometido. }\end{array}$ \\
\hline \multirow{5}{*}{ Esportes } & $\begin{array}{l}\text { Pontos negativos: As demais atividades de } \\
\text { esportes e lazer que são feitas fora da } \\
\text { quadra, são improvisadas no entorno da } \\
\text { quadra, não existindo um espaço próprio } \\
\text { para cada atividade. }\end{array}$ \\
\hline Esportes & $\begin{array}{l}\text { Ponto negativo: Os equipamentos de baixa } \\
\text { qualidade vão aos poucos estragando e } \\
\text { ficando impróprio para o uso. }\end{array}$ \\
\hline
\end{tabular}

Fonte: Elaborado com base em levantamento de campo

Em outubro de 2003 foi inaugurado o prédio atendendo a todas as necessidades que existiam, anos depois as necessidades foram mudando, até chegar no ponto que foi preciso fazer uma grande reforma no colégio. Os motivos foram vários, mas o principal foi o problema encontrado na sua estrutura. Os alunos passaram próximo de um ano estudando das dependências do ginásio de esporte, aguardando a reforma ser concluída.

Analisando os ambientes e seus layouts conclui-se que a sua estrutura deixa a desejar em diversos fatores como a falta de espaços externos projetados para a prática de atividades, a falta de salas para desenvolver atividades especificas como dança, teatro e música e etc. O refeitório não comporta o número de alunos, e suas salas de aula juntamente com os laboratórios não tem o mobiliário adequado e 
confortável, tornando assim o prédio incapaz de atender as necessidades da atualidade para o ensino integral.

\section{COLÉGIO POSITIVO INTERNACIONAL}

Colégio Positivo Internacional foi selecionado para análise por apresentar uma série de aspectos arquitetônicos considerados positivos a partir da pesquisa bibliográfica localizado. O colégio está localizado em Curitiba, Paraná, projetado pelo escritório Manoel Coelho Arquitetura e Design e construído em 2013 com cerca de $5.000 \mathrm{~m}^{2}$.

Quadro 2 - Síntese analítica do Colégio Positivo Internacional

(Continuação para as próximas páginas)

\begin{tabular}{|l|l|l|}
\hline Setores & Pontos positivos ou negativos & Registro fotográfico \\
\hline $\begin{array}{l}\text { Área } \\
\text { externa }\end{array}$ & $\begin{array}{l}\text { Ponto positivo: Uma grande área verde no } \\
\text { entono do prédio com arvores, gramado e } \\
\text { área de convivência externa. }\end{array}$ \\
\hline $\begin{array}{l}\text { Área } \\
\text { externa }\end{array}$ & $\begin{array}{l}\text { Pontos positivos: Existe estacionamento } \\
\text { privativo para funcionários, pais e } \\
\text { professores e nas janelas são utilizados } \\
\text { brises de metal para proteger contra os } \\
\text { raios solares. } \\
\text { externa }\end{array}$ & $\begin{array}{l}\text { Pontos positivos: Tem uma via interna para } \\
\text { chegada no colégio e evitar } \\
\text { congestionamento no trânsito. Tem } \\
\text { também uma cobertura metálica } \\
\text { protegendo quem entra e sai do prédio nos } \\
\text { dias de chuva e sol forte. }\end{array}$ \\
\hline
\end{tabular}


(Continuação para as próximas páginas)

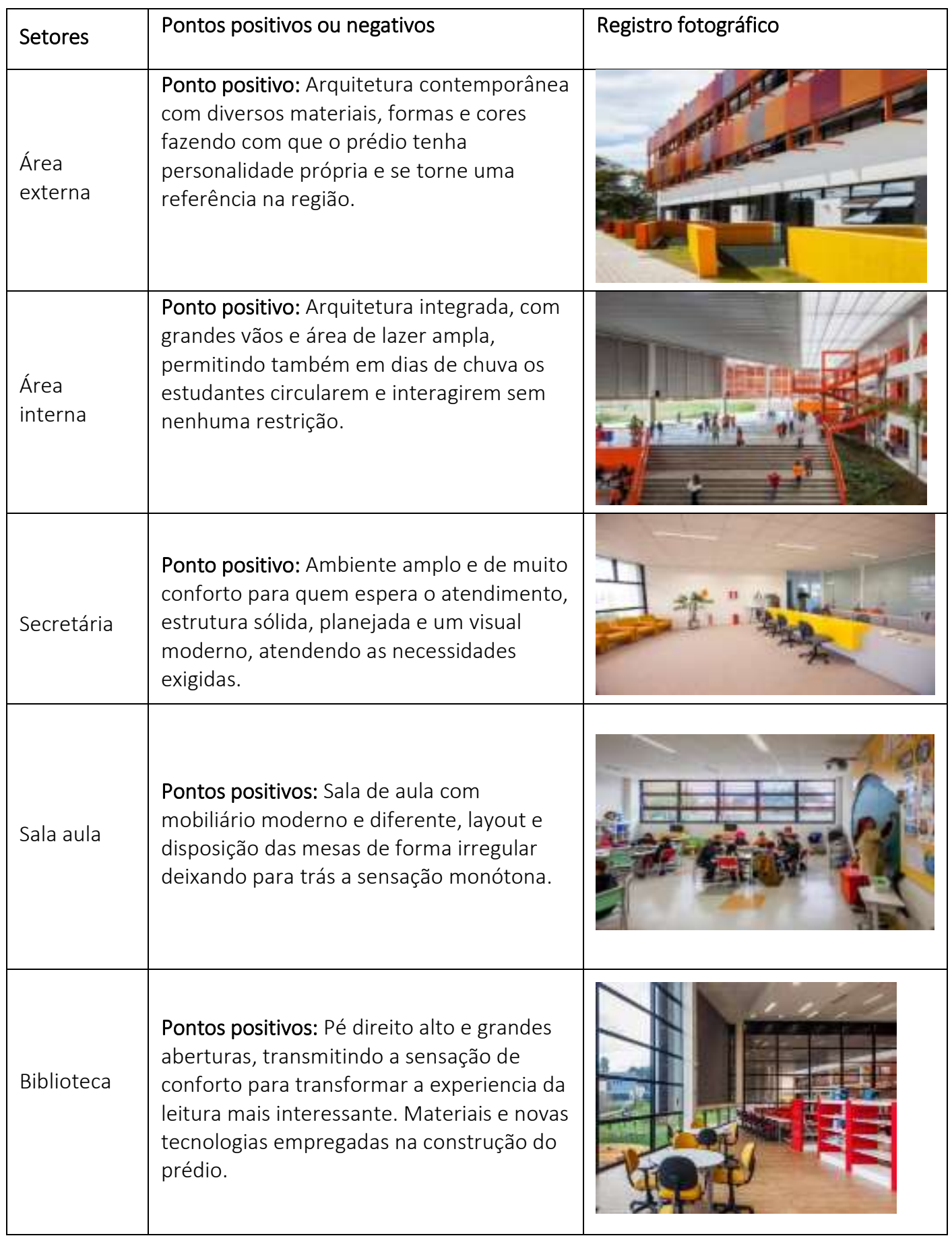




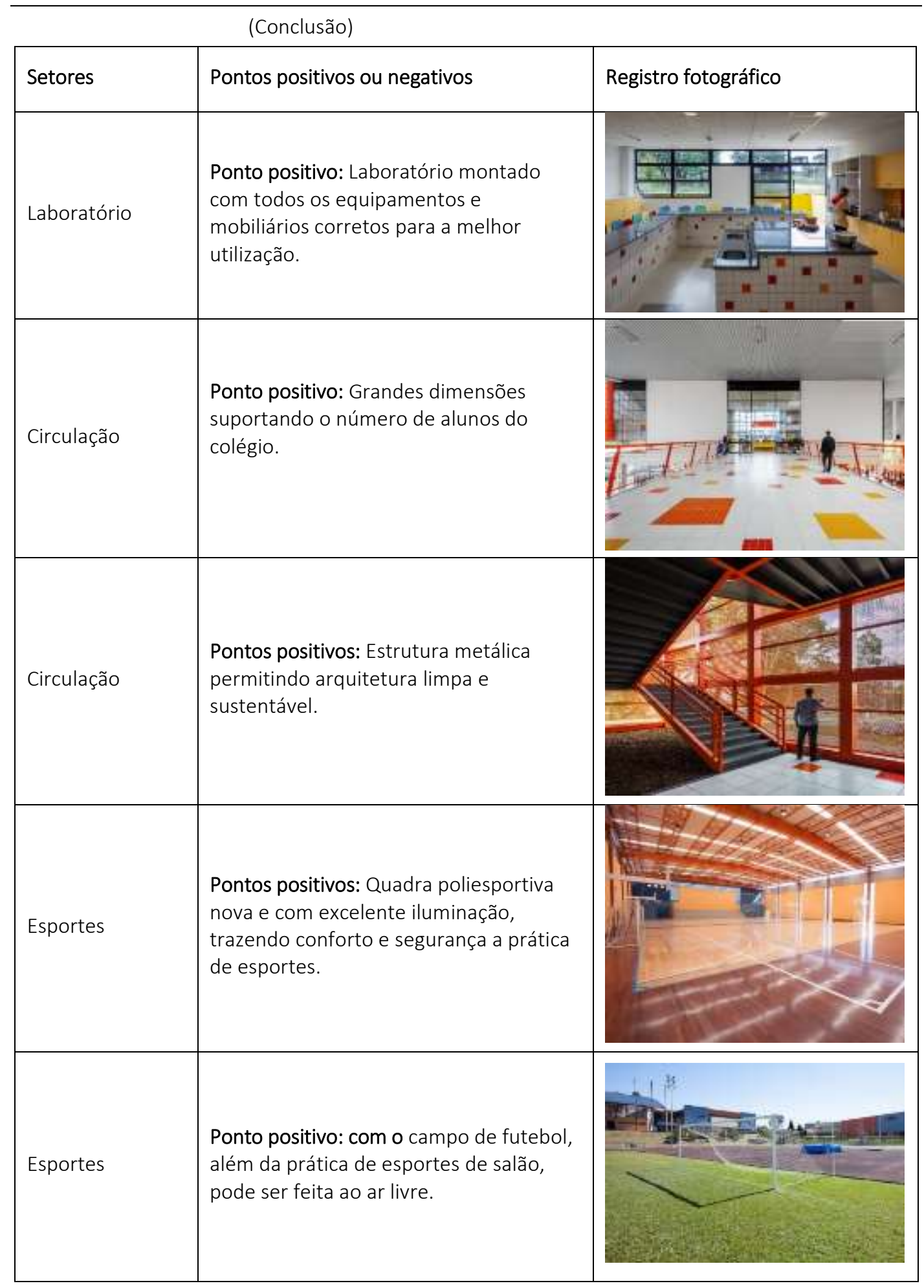

Fonte: Tabela elaborada com base em site Archdaily Brasil. 
Segundo Abrão e Coelho (2013), na concepção do projeto foram adotadas várias estratégias sustentáveis, como: o maior aproveitamento do terreno irregular sem grandes movimentações de terra, minimizando a agressão ao solo; cuidados com os resíduos da obra; localização dos ambientes voltados para o norte, aproveitando a luz natural e a ventilação cruzada; reutilização das águas pluviais, entre outros. Todos esses aspectos fazem com que a edificação se torne referência não somente em estética, mas também em sua essência, e em ambientes escolares, tal característica é de suma importância. O Colégio Positivo Internacional foi a primeira escola no Brasil a receber o certificado ambiental LEED nível ouro.

\section{DIRETRIZES PROJETUAIS PARA UMA ESCOLA EM CAÇADOR}

Considerando os estudos realizados, os caminhos a serem tomados para desenvolver um projeto de qualidade e atender as necessidades reais dos estudantes de uma escola de ensino médio integral, são apontadas as seguintes diretrizes para o projeto:

a) Aproveitar o máximo possível do terreno, respeitando e não agredindo a sua topografia;

b) Valorizar a estética e o conforto para melhor atender as necessidades dos estudantes;

c) Desenvolver uma arquitetura integrada, pensando nos fluxos e compartilhamento para instigar os alunos a ir à escola;

d) Criar espaço interno e externo multifuncional para as crianças e jovens interagirem e se divertirem;

e) Projetar grandes aberturas permitindo a entrada da ventilação e insolação melhorando o conforto térmico no prédio;

f) Conceber em projeto pé direito duplo em determinados ambientes para transmitir variadas sensações;

g) Desenvolver salas e laboratórios com diferentes formas, cores e materiais;

h) Trazer as tecnologias para as salas de aulas, facilitando o aprendizado do aluno;

i) Integrar o prédio com paisagismo interno e externo, aproveitando o que a 
natureza tem de melhor para oferecer;

\section{CONCLUSÃO}

Conclui-se que desde a implantação do ensino integral no Brasil cresceu a exigência por um espaço adequado para os estudantes e servidores do ensino médio. O ensino integral foi criado afim de auxiliar ainda mais na formação profissional e social de cada estudante, proporcionando a eles uma educação diferenciada, incluindo além das matérias obrigatórias, aulas culturais, sociais, projetos para desenvolvimento da criatividade, disciplinas eletivas, entre outras práticas que valorizam os saberes e ao fazeres.

Desse modo para o desenvolvimento da capacidade e habilidade de cada estudante faz-se necessário a criação de espaços adequados e planejados para a realização das atividades extras da grade curricular, escolas com mais tecnologia para fornecer segurança para alunos e servidores. E ambientes que possam ser facilmente transformados de salas de aula para oficinas, permitindo ampliar as possibilidades de aprendizado.

Um espaço seguro, amplo, convidativo, confortável e aconchegante, faz com que os jovens se motivem para ir à escola, nos dias atuais as escolas são construídas sem planejamento, padronizadas, muradas, sem vida, sem cores, sem laboratórios apropriados, salas apertadas, gerando com isso alunos desmotivados e inseguros sendo obrigados a irem à escola.

Aliando a arquitetura ideal com o ensino integral de qualidade, pode-se afirmar que o programa só tende a crescer e evoluir constantemente, um depende e complementa o outro. Um prédio com bons materiais, planejamento e técnicas construtivas, tende a transmitir maior segurança e conforto para seus usuários, refletindo diretamente na qualidade do ensino o nos resultados finais.

\section{REFERÊNCIAS}

ABRÃO; COELHO, Antonio; Manoel. Colégio Positivo Internacional. Disponível em: $<$ https://www.archdaily.com.br/br/872442/colegio-positivo-internacional-manoelcoelho-arquitetura-e-design>. Acesso em: 02 de junho de 2018. 
BASTOS, Maria Alice Junqueira. Artigo Site AU. A escola-parque: ou o sonho de uma educação completa (em edifícios modernos). Edição 178. Publicada em: janeiro de 2009. Disponível em: <http://au17.pini.com.br/arquitetura-

urbanismo/178/artigo122877-1.aspx> Acesso em: 01 de maio de 2018.

COOK; ROBOTHAM, Sir Peter; Gavin. Escola de Arquitetura Abedian. Disponível em: $<$ https://www.archdaily.com.br/br/01-177510/escola-de-arquitetura-abedianslash-crab-studio>. Acesso em: 02 de junho de 2018.

DC - Diário Catarinense. Veja quais são as 21 escolas de SC candidatas à implantação de ensino médio integral em 2018. Publicada em: 11 de setembro de 2017. Disponível em: <http://dc.clicrbs.com.br/sc/estilo-devida/noticia/2017/09/veja-quais-sao-as-21-escolas-de-sc-candidatas-aimplantacao-de-ensino-medio-integral-em-2018-9894208.html> Acesso em: 03 de maio de 2018.

ESTADÃO. A educação integral no Brasil com foco no ensino médio. Disponível em: <http://educacao.estadao.com.br/blogs/de-olho-na-educacao/a-educacaointegral-no-brasil-com-foco-no-ensino-medio/> Acesso em: 03 de maio 2018.

ESTADÃO. Arquitetura escolar e seu papel no aprendizado. Entrevista com Doris Kowaltowski. Disponível em:<http://educacao.estadao.com.br/noticias/geral,aarquitetura-escolar-e-seu-papel-no-aprendizado,70002202508> Acesso em: 23 de abril de 2018.

GOULART, Beatriz. Conversa entre arquitetura e educação refletem a relação do bairro com a escola. Matéria publicada em: 1 de abril de 2016. Disponível em: $<$ http://fundacaotelefonica.org.br/noticias/conversas-entre-arquitetura-eeducacao-refletem-a-relacao-do-bairro-com-a-escola/> Acesso em: 01 de maio de 2018.

KOWALTOWSKI, Doris C.C.K. Arquitetura escolar o projeto do ambiente de ensino. 1'a edição. São Paulo: Oficina de Textos, 2011.

MARTINS, Helena. Censo aponta que escolas públicas ainda têm deficiências de infraestrutura. Disponível em:

<http://agenciabrasil.ebc.com.br/educacao/noticia/2018-01/censo-aponta-queescolas-publicas-ainda-tem-deficiencias-de-infraestrutura>. Acesso em: 04 de maio de 2018.

MEC. Educação integral. Disponível em:

<http://educacaointegral.mec.gov.br/?id=9> Acesso em: 21 de abril de 2018. 
MENEZES, Ebenezer Takuno de; SANTOS, Thais Helena dos. Verbete sistema educacional brasileiro. Dicionário Interativo da Educação Brasileira - Educabrasil. São Paulo: Midiamix, 2001. Disponível em:

<http://www.educabrasil.com.br/sistema-educacional-brasileiro/>. Acesso em: 04 de maio de 2018.

Portal CDR. Inicia ensino médio integral em escolas de Caçador. Publicado em 14 de fevereiro de 2012. Disponível em:

<http://www. portalcdr.com.br/noticiasDetalhes. php?id=1494> Acesso em: 04 de maio de 2018. 